own working principles, which are simply the minimum assumptions necessary in order to make sense of a world in space and time, then Kant himself must take explicit account of space and time, and see to it that any more abstract principles of his own, which he may be able to extract from an analysis of pure logical forms, shall be given a spatio-temporal form, that is, 'schematized', before he can set them forth as valid for scientific thought. Prof. Paton's understanding of this, and his demonstration that Kant also understood it, constitute not the least of the merits of this book.

Kant's philosophy does not lend itself to quick study and epigrammatic judgment; but those who are prepared to study it seriously and in detail, as it demands, will do well to take Prof. Paton as their guide. His commentary is indispensable to those who wish to obtain a clear and balanced view of the fundamental principles of one of the greatest philosophies of modern times.

\title{
Comparative Biochemistry
}

An Introduction to Comparative Biochemistry By Dr. Ernest Baldwin. Pp. xviii +112 . (Cambridge: At the University Press, 1937.) $5 s$. net.

UNTIL recently, the criteria of zoological and botanical relationships were, in the main, qualities of external or internal structure, or of functional behaviour. The possibly more intimate and certainly less obvious resemblances and differences between different animal types, in the chemical make-up of their tissues and body fluids and in their metabolic habits, have only recently begun to come within the sphere of established knowledge. It is as a direct result of the new methods which have been developed in biochemistry, particularly as an outcome of increased accuracy in dealing analytically with very small quantities of material, that information has accumulated in the last few years regarding these matters, throwing a flood of light on the ways in which the physical and chemical problems presented to different types of living organisms at various stages in their evolutionary history have been overcome.

In this book an outline of recent advances in this relatively untrodden field-an outline that is never far from the available experimental findings-is presented in an admirably succinct way by Dr. Baldwin. Beginning with a consideration of the osmotic difficulties of sea- and freshwater fauna and how these are met, the author proceeds to the devices used by land animals for conservation of water, and the biological significance of the different ways in which nitrogen is excreted in different groups of land and sea animals, particularly in relationship to the ornithine cycle and purine metabolism. A section is devoted to the strange distribution of the two phosphagens. Recent work on the biochemistry of the supply of oxygen to the tissues in relation to respiratory pigments is summarized, and is followed by a brief descriptive account of some pyrrol, indol and carotene pigments. This last chapter on pigments seems a trifle abrupt, and less well woven than the earlier chapters into the general evolutionary story.

It is doubtful whether the word uræmia (p. 32 et seq.), normally used clinically to describe a definitely pathological condition which may occur irrespective of the level of urea in the blood, is the wisest one to use to describe a physiological condition in which there is a high content of urea in the blood and tissues. It is not quite clear why, if urea were produced in the cleidoic egg, it should disturb osmotic relationships (p. 47), since, apart from the wall of the urinary bladder and the gills of elasmobranchs, most tissues seem to be freely permeable to this substance. It would have been interesting to have had the author's views on the relationship of the recent findings of W. L. Davies, that trimethylamine oxide occurs in appreciable quantities in the urine and milk of dairy cows after they have eaten various beet by-products, with the statement (in the section beginning on p. 43) that it is only in the excreta of marine teleosts that this substance occurs. Does the normal diet of these animals contain large quantities of betaine or related compounds? Is the occurrence of trimethylamine oxide in the excreta more a reflection of the type of compound in the ingesta than of any fundamental metabolic peculiarity?

In case there is virtue in the fact that the reviewer read through this book from cover to cover with the greatest pleasure in a single sitting, let it be put on record. Dr. Baldwin's book may be confidently recommended as a delightfully yet firmly written introduction to this infant science. Sir Frederick Hopkins contributes a characteristic foreword. 